\title{
Intra-Specific Variability in Whorl Growth-Rate among Land Gastropods with Conispirally-Coiled Shells
}

\author{
Jean Béguinot ${ }^{\mathrm{a}^{*}}$ \\ a Université de Bourgogne, 6 Boulevard Gabriel, 21000 Dijon, France.
}

Author's contribution

The sole author designed, analysed, interpreted and prepared the manuscript.

Article Information

DOI: 10.9734/ARRB/2021/v36i1230463

(1) Dr. Saleha Sadeeqa, Lahore College for Women University, $\frac{\text { Editor(s): }}{\text { Pakistan. }}$

Reviewers:

(1) Paola Lombardo, Italy.

(2) N.Malarkodi, Bangalore University, India.

Complete Peer review History, details of the editor(s), Reviewers and additional Reviewers are available here: https://www.sdiarticle5.com/review-history/77388

Original Research Article

Received 06 October 2021

Accepted 13 December 2021

Published 14 December 2021

\begin{abstract}
For most conispirally-coiled Gastropods with determinate growth, the geometry of spirally-winding whorls is usually constrained by a strong negative correlation between whorl growth rate and the number of whorls reached at adulthood, as originally reported by the late S.J. Gould. Yet, beyond the tight control of shell-shape at the species level - resulting from this constraint - what about the amplitude of the intra-specific variability of whorl growth-rate, partly contributing to the variability of the overall shell-size at the species level? I address the issue by designing and implementing a new, indirect method for routinely evaluating whorl growth-rate, thereby aiming at considerably saving measurement time, and making it possible to easily achieve repeated measurements across samples large enough to reach statistical significance. This approach was applied to a series of eight common land snail species. The amplitude of intra-specific variability in whorl growth, evaluated this way, proves: (i) being markedly different among the eight investigated species (by a factor that can exceed 2x); (ii) being, yet, high enough, in all cases, to require compensating variations in the adult number of whorls, so as to limit the resulting consequences on the amplitude of the intra-specific variability of adult shell-size. Despite those marked differences in the amplitudes of intra-specific variability of whorl growth-rate among species, no significant relationship was observed between intraspecific variability of whorl growth rate and speciesspecific shell-shape types (discoidal/globular/elongate) and only weak positive relationship was
\end{abstract}


observed with species-specific typical shell sizes. However, a rather strong positive correlation was found, as expected, between the degree of intra-specific variability of the whorl growth-rate and the degree of intra-specific variability of the number of whorls reached at adulthood (with the yet unexplained exception of one among the eight investigated species).

Keywords: Land snail; shell geometry; shell-size regulation.

\section{INTRODUCTION}

Growth-rate in animals is one among important phenotypic parameters subjected to appreciable intra-specific variability (i.e. inter-individual variability within a same species) [1]. And the range of intra-specific variability in growth-rate is often wide enough to require some corrective compensation by means of opposite variations of the growth duration, at least in those animal species having determinate-growth (i.e. having adult body size constrained within a defined and relatively narrow range of values). This compensation implying, thus, some negative covariance between the average growth-rate and the growth duration before reaching adulthood.

One may anticipate that the degree of intraspecific variability in body growth-rate may substantially differ among species - even among those species having determinate adult size. Of course, such differences in the intra-specific variability of growth-rate among species having determinate adult shell-size will:

(i) result in a corresponding difference in the achieved degree of control of adult body size or, otherwise,

(ii) be accommodated by a corresponding difference in the efficiency of the compensation by means of growthduration.

The body growth of Gastropods with conispirallycoiled shells, such as land snails, can be quantified in term of the shell growth itself, since although shell volume not necessarily strictly identifies to the harboured soft-body volume, the former usually tightly reflects the latter [2]. Therefore, here, the intra-specific variability affecting body-growth can be relevantly assessed by considering the intra-specific variability affecting shell-growth itself and, more exactly, the progressive growth variability of the spirally-coiling whorl. While the compensating duration of body-growth will be, here, relevantly expressed in term of the number of whorls reached at adulthood, as such called to covary negatively with the degree of whorl growth [2-4].
Let still be a little more precise: the "whorl-size" i.e. the whorl-section size reached after a given number of spiral turns - depends both (i) on the size of the first whorl and, then, (ii) on the expanding ratio of the exponentially increasing whorl section. Each of these two contributions to the growing whorl size being likely submitted to intra-specific variability for its own.

Now, from a practical point of view, accurately measuring, shell by shell, the size of the first whorl on the one hand and, then, the expanding rate of the whorl section on the other hand, features rather difficult to achieve properly. And would become, accordingly, excessively timeconsuming - at least when applied to the large numbers of specimens usually required to accurately assess the degree of intra-specific variability of both the first-whorl size and the whorl expanding rate. Fortunately, it reveals possible to greatly simplify this evaluation by relevantly computing as a whole the combined contributions of these two growth factors to the resulting final shell size. This can be achieved in term of a "whorl-growth parameter" ' $\gamma$ ', computed in a way originally proposed in reference [2].

So that, finally, the intra-specific variability affecting the whorl- and the resulting shell-growth process will be appropriately assessed by considering the degree of intra-specific variability of the whorl-growth parameter $\mathrm{y}$.

Thanks to what, it becomes far easier, in practice, to assess and then to compare the respective degrees of intra-specific variability affecting the process of whorl-growth and the resulting shell growth, among various common land snail species.

\section{MATERIALS AND METHODS}

\subsection{Materials}

Eight species of land snails, each of them known to have determinate growth, were considered for the study, namely: Cepaea nemoralis (Linneaus 1758), Cornu aspersum (O.F. Müller 1774), Monacha cartusiana (O.F. Müller 1774), 
Helicodonta obvoluta (O.F. Müller 1774), Pomatias elegans (O.F. Müller 1774), Chondrula tridens (O.F. Müller 1774), Ena montana (Draparnaud 1801), Zebrina detrita (O.F. Müller 1774).

This series of eight species was selected to encompass the various kinds of overall shell shapes: three species have globular shells; one has discoidal shell and four have more or less elongate shells.

For each species, a presumably representative population of individuals was sampled:

* Cepaea nemoralis: 103 sampled adult individuals, located at Saint Vallerin (Saône \& Loire department, south Burgundy);

* Cornu aspersum: 33 sampled adult individuals, located at Salins-les-Bains (Jura department, Franche-Comté);

* Monacha cartusiana: 115 sampled adult individuals, located at Saint Vallerin (Saône \& Loire department, south Burgundy);

* Helicodonta obvoluta: 83 sampled adult individuals, located at Blois-sur-Seille (Jura department, Franche-Comté);

* Pomatias elegans: 110 sampled adult individuals, located at Saint Vallerin (Saône \& Loire department, south Burgundy);

* Chondrula tridens: 51 sampled adult individuals, located at Germagny (Saône \& Loire department, south Burgundy);

* Ena montana: 28 sampled adult individuals, located at Val-Suzon (Côte d'Or department, central Burgundy);

* Zebrina detrita: 43 sampled adult individuals, located at Le Parrotier (Vaucluse department, Provence).

\subsection{Methods}

For each individual shell, both the number of whorls $\mathrm{n}_{\mathrm{a}}$ reached at adulthood and the shell-size (i.e. diameter $\mathrm{D}_{\mathrm{a}}$ for globular and discoidal shells or height $\mathrm{H}_{\mathrm{a}}$ for elongate shells) were measured:

- the shell size by using a numeric calliper (to the precision of $1 / 10 \mathrm{~mm}$ );

- the number $n_{a}$ of whorls at adult stage by careful examination of the shell, examined from the apex, according to the procedure prescribed in reference [5], using a stereomicroscope at moderate magnification, a procedure which typically allows reaching a precision at the level of $1 / 10$ whorl revolution. Subsequently, the whorl-growth parameter ' ' is computed according to the procedure described in reference [2] and briefly recalled in the Appendix. "Adult" shells were recognized and selected on the basis of the aspect of aperture (in particular peristome) as suggested in reference [5].

Thus, beside the number of whorls $n_{a}$ and the overall shell-size at adulthood, the whorl-growth parameter $\mathrm{y}$ (which, together with $\mathrm{n}_{\mathrm{a}}$, determine the adult shell-size) is conveniently and easily made available for each shell, in the population under study.

The degree of intra-specific variability affecting the process of whorl-growth (and the resulting shell-growth itself) was assessed quantitatively by assessing the coefficient of variation of the whorl-growth parameter $\mathrm{Y}$ among the individuals of the sampled population for each studied species.

Subsequently, the amplitudes of the intra-specific variability of the whorl-growth parameter $\gamma$, thus assessed for each species, were compared, (i) at first between the eight species considered as a whole and then (ii) between species considered two by two. The statistical significance of these comparisons was evaluated by implementing the conventional Bartlett-test in order to check whether recorded differences could be considered as actually meaningful or likely attributable to chance alone.

\section{RESULTS}

The coefficients of variation (ratio of standarddeviation to the mean) of the whorl-growth parameter $y$ for each eight studied species of land snails are given in Table 1. Bartlett-tests were applied to the standard deviation of the whorl-growth parameter $y$ in each of the eight studied species, after log-transformation of $\gamma$, to improve the normality of the distributions of $\mathrm{y}$. The test was applied first to the eight species considered together and, subsequently, to the eight species considered separately two by two (i.e., 28 couples of species).

Very highly significant differences do exist between the coefficients of variation of $y$ among the eight studied species: $T=58.1$, d.f. $=7, \mathrm{p}<<$ 0.001 . 
Fig. 1 further provides the $\mathrm{T}$ values for the Bartlett-tests applied to each of the 28 couples of species. Two distinct sub-groups of species can be distinguished (underlined in grey in Fig. 1), namely:

\{Ena montana, Helicodonta obvoluta, Chondrula tridens $\}$ on the one hand

\{Pomatias elegans, Zebrina detrita, Monacha cartusiana, Cornu aspersum\} on the other hand.

This distinction is established considering the ranges of intra-specific variability of the whorlgrowth parameter $\mathrm{y}$ of those species belonging respectively to one or the other of the two subgroups. According to results provided in Fig. 1, the four species of the second group exhibit very significantly larger ranges of intra-specific variability of parameter $\mathrm{y}$ than any one of the three species of the first group (Bartlett test, $p>$ 0.01 or often $p>0.001$ ), while only weak, non- significant statistical differences are retained within each of the two sub-groups of species. Cepaea nemoralis, for its own, is in an intermediate position between these two subgroups.

Fig. 2 provides a graphical illustration of the preceding results, synthetizing both the assessed degrees of variability of whorl-growth parameter $\mathrm{y}$ and the level of statistical significance of the recorded differences in this respect.

\section{DISCUSSION}

Intra-specific variability in some phenotypic traits may have important biological correlates. For example, as already emphasized above, in animal species (including other kinds of animal species than land snails) having determinate growth (i.e.: limited disparity in adult size), the intra-specific variations in growth-rate are usually compensated by an opposite response of the

Table 1. The coefficient of variation of the whorl-growth parameter $y$ (C.V. of $y$ ) for eight species and the number $\mathbf{N}$ of sampled individuals per species from which are computed the C.V. of $Y$

\begin{tabular}{lllllllll}
\hline species & $\begin{array}{l}\text { Ena } \\
\text { mont. }\end{array}$ & $\begin{array}{l}\text { Helico. } \\
\text { obvol. }\end{array}$ & $\begin{array}{l}\text { Chond. } \\
\text { tridens }\end{array}$ & $\begin{array}{l}\text { Cepaea } \\
\text { nemor. }\end{array}$ & $\begin{array}{l}\text { Pomat. } \\
\text { elegans }\end{array}$ & $\begin{array}{l}\text { Zebrina } \\
\text { detrita }\end{array}$ & $\begin{array}{l}\text { Monac. } \\
\text { cartus. }\end{array}$ & $\begin{array}{l}\text { Cornu } \\
\text { aspers. }\end{array}$ \\
\hline $\mathbf{N}$ & 28 & 83 & 51 & 103 & 110 & 43 & 115 & 33 \\
C.V. of Y & 0.0489 & 0.0558 & 0.0644 & 0.0759 & 0.0942 & 0.0945 & 0.0976 & 0.1140 \\
\hline
\end{tabular}

\begin{tabular}{|c|c|c|c|c|c|c|c|c|}
\hline$\frac{\text { BARTLETT }}{\underline{\text { TEST }}}$ & $\begin{array}{c}\text { Ena } \\
\text { montana }\end{array}$ & $\begin{array}{l}\text { Helicod. } \\
\text { obvoluta }\end{array}$ & $\begin{array}{c}\text { Chondru. } \\
\text { tridens }\end{array}$ & $\begin{array}{c}\text { Cepaea } \\
\text { nemoralis }\end{array}$ & $\begin{array}{l}\text { Pomatias } \\
\text { elegans }\end{array}$ & $\begin{array}{c}\text { Zebrina } \\
\text { detrita }\end{array}$ & $\begin{array}{c}\text { Monacha } \\
\text { cartus. }\end{array}$ & $\begin{array}{c}\text { Cornu } \\
\text { aspersum }\end{array}$ \\
\hline $\begin{array}{c}\text { Ena } \\
\text { montana }\end{array}$ & 0.0 & & & & & & & \\
\hline $\begin{array}{l}\text { Helicod. } \\
\text { obvoluta }\end{array}$ & 0.7 & 0.0 & & & & & & \\
\hline $\begin{array}{l}\text { Chondru. } \\
\text { tridens }\end{array}$ & 2.3 & 1.2 & 0.0 & & & & & \\
\hline $\begin{array}{c}\text { Cepaea } \\
\text { nemoral. }\end{array}$ & $\begin{array}{c}6.5 \\
* \\
\end{array}$ & $\begin{array}{l}7.8 \\
* * \\
\end{array}$ & 1.7 & 0.0 & & & & \\
\hline $\begin{array}{l}\text { Pomatias } \\
\text { elegans }\end{array}$ & $\begin{array}{l}13.1 \\
* * *\end{array}$ & $\begin{array}{l}21.6 \\
* * *\end{array}$ & $\begin{array}{l}8.1 \\
* *\end{array}$ & $\begin{array}{c}4.3 \\
*\end{array}$ & 0.0 & & & \\
\hline $\begin{array}{c}\text { Zebrina } \\
\text { detrita }\end{array}$ & $\begin{array}{l}12.1 \\
* * *\end{array}$ & $\begin{array}{l}16.5 \\
* * *\end{array}$ & $\begin{array}{l}6.9 \\
* *\end{array}$ & 3.3 & 0.0 & 0.0 & & \\
\hline $\begin{array}{l}\text { Monacha } \\
\text { cartus. }\end{array}$ & $\begin{array}{l}15.7 \\
* * *\end{array}$ & $\begin{array}{l}27.8 \\
* * *\end{array}$ & $\begin{array}{l}11.4 \\
* * *\end{array}$ & $\begin{array}{l}7.8 \\
* *\end{array}$ & 0.5 & 0.10 & 0.0 & \\
\hline $\begin{array}{c}\text { Cornu } \\
\text { aspersum }\end{array}$ & $\begin{array}{l}17.8 \\
* * *\end{array}$ & $\begin{array}{l}26.7 \\
* * *\end{array}$ & $\begin{array}{l}13.3 \\
* * *\end{array}$ & $\begin{array}{l}9.5 \\
* *\end{array}$ & 2.4 & 1.30 & 1.10 & 0.0 \\
\hline
\end{tabular}

Fig. 1. Summary of $T$ values obtained in the Bartlett test for the comparisons between the standard deviations of the (log-transformed) whorl-growth parameter $y$ for each of the 28 couples of species. One / two / three / asterisks respectively denote statistical-significance thresholds $p<0.05 / p<0.01 / p<0.001$.

No asterisk suggests non-significant differences $(p>0.05)$. Comments in text 


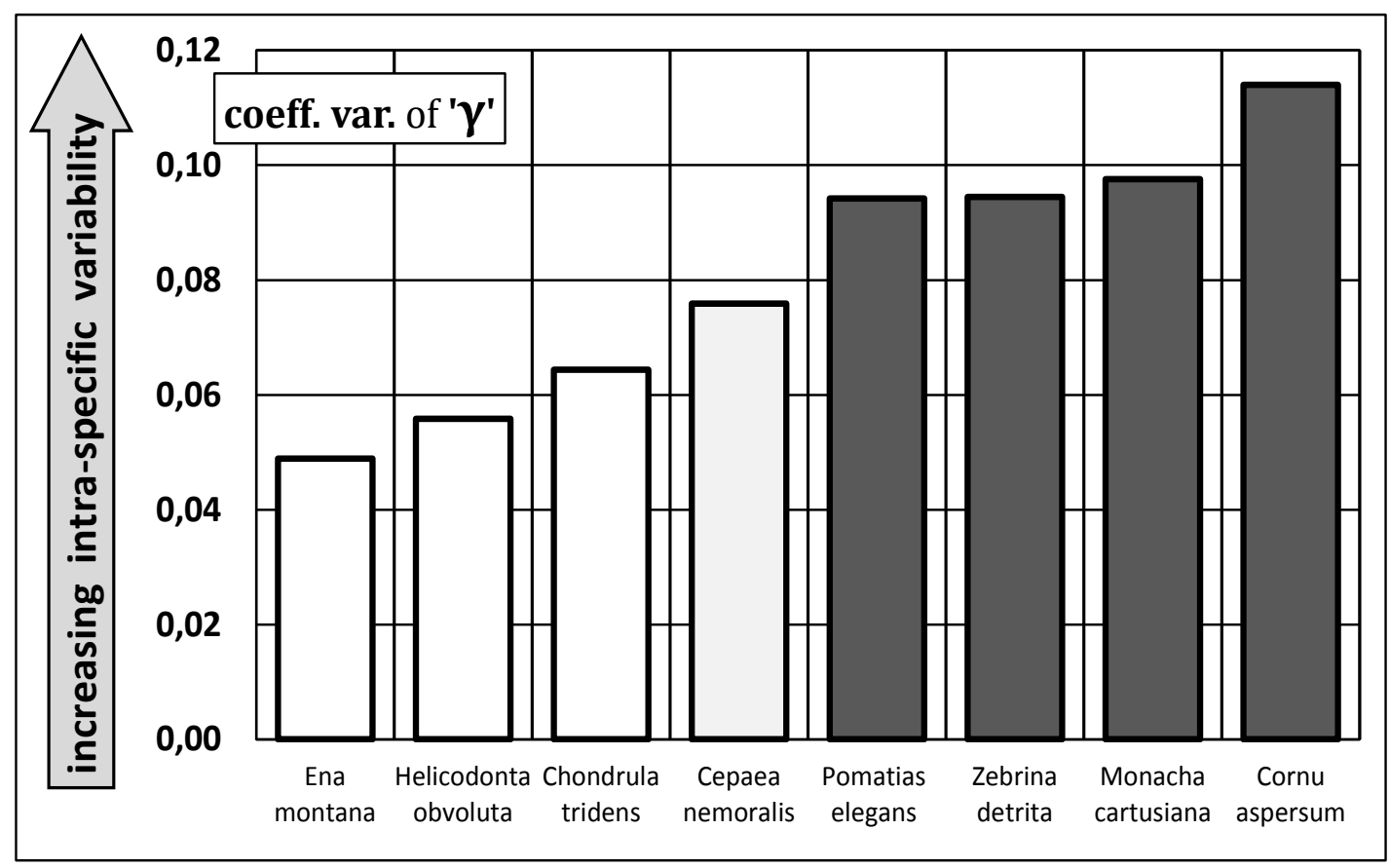

Fig. 2. Histogram of the coefficients of variation of the whorl-growth parameter $y$ ("coeff. var. of $Y$ ") for each eight studied species (from Table 1), with differentiation in the degree of shading suggesting the levels of statistical difference among species

growth-duration after which the adult stage size is reached. And, similarly, focusing now on shelled gastropods species, the intra-specific variations in whorl-growth parameter $Y$ are usually partially compensated by an opposite response of the number of whorls $\mathrm{n}_{\mathrm{a}}$ reached at adulthood. What is highlighted by a negative covariance between $\mathrm{y}$ and $\mathrm{n}_{\mathrm{a}}$ [2-4].

Accordingly, I assess, and then compare, the respective amplitudes of this intra-specific variability of $\mathrm{y}$. And this, for as large as possible a series of species. And, subsequently, I test for possible statistically-significant differences in this respect, according to species identity.

\subsection{The Magnitude of the Intra-Specific Variability of Whorl-Growth Parameter}

The results point to moderate levels of intraspecific variability of whorl-growth parameter $\mathrm{Y}$, with the coefficient of variations (i.e. ratio of standard deviation to the mean) of $y$ ranging from 0.049 (for Ena montana) to 0.114 (for Cornu aspersum), with the six other studied species interspacing themselves rather regularly between these extremal values (Fig. 2). Thus, the amplitude of the intra-specific variability of $\mathrm{y}$ can differ, from species to species, by a factor up to $2.3(0.114 / 0.049)$, which is rather substantial. Further considering the level of statistical significance of these comparisons shows that, schematically, the studied species distribute themselves into two groups:

(i) rather moderate levels of intra-specific variability of $\mathrm{Y}$ for \{Ena montana, Helicodonta obvoluta and Chondrula tridens\} on the one hand and

(ii) significantly more pronounced levels of intra-specific variability of $\mathrm{y}$ for \{Pomatias elegans, Zebrina detrtita, Monacha cartusiana and Cornu aspersum\} on the other hand.

The last species, Cepaea nemoralis featuring in intermediate position between these two groups (see Figs. 1 and 2).

Note that Pomatias elegans singularizes itself (as belonging to sub-class Prosobranchia) in being deemed to show some sexual dimorphism which materializes in practice by some faint difference between sexes as regards the range of adult shell-size. Therefore, this might possibly blur, and irrelevantly increase to some extent, the real magnitude of the genuine amplitude of the intra-specific variability of $\mathrm{Y}$ in this species. However, the rather "intermediate" positioning of Pomatias elegans among the other studied species would suggest that this faint 
dimorphism might not have major influence in this respect.

\subsection{Possible Correlates between the Degree of Intra-Specific Variability of Whorl-Growth-Parameter $\mathrm{y}$ and Major, Species-Specific Shell-Characteristics}

At first, the amplitude of the intra-specific variability of the whorl-growth parameter $\mathrm{y}$ could by no means be relevantly related to the main types of shell-shape - discoidal/globular/more or less elongate: thus, the group of species with moderate levels of intra-specific variability of $Y$ includes two elongate and one discoid species, the group with more pronounced levels of intraspecific variability of $y$ includes two elongate and two globular species and, finally, the intermediate species is globular. A repartition which, as a whole, fails to highlight any significant relatedness between the amplitude of the intraspecific variability of $\mathrm{Y}$ and the main types of shell-shapes.

On the other hand, the amplitude of the intraspecific variability of $\mathrm{Y}$ seems to positively correlate with a typical index of adult shell-size (quantified by $\left[h \cdot d^{2}\right]^{1 / 3}$, with $\mathrm{h}$ and $\mathrm{d}$ being the shell-height and shell-diameter): Fig. 3. Yet, the correlation reveals in fact being hardly statistically significant: $r=0.643, n=8, p=0.043$ (directional), but $p=0.085$ (non-directional): Fig. 3.

\subsection{Influence of the Intra-Specific Variability in Whorl-Growth $y$ upon the Compensatory Answer of the Number of Whorls at Adulthood}

As already mentioned, it has been shown previously that to buffer, at least partially, the disparity in adult shell size, the variations of the whorl-growth parameter $\mathrm{Y}$ are actually compensated by some degree of opposite variations of the number $n_{a}$ of whorls reached at adulthood [2-4]. It could then be reasonably expected that the larger the amplitude of the intra-specific variability of $\mathrm{\gamma}$, the stronger the negative covariance between $n_{a}$ and $y$ (aptly quantified by either the coefficient of determination $r^{2}$ or by the coefficient of correlation $r$ of this covariance).

Indeed, based on previously reported values of $r^{2}$ and $r$ for the negative covariance between $n_{a}$ and $Y$ for each eight studied species [2], a strongly significant positive correlation exists between the amplitude of the intra-specific variability of $y$ and the coefficient of determination $r^{2}$ of the negative covariance between $n_{a}$ and $y$ : Fig. 4.

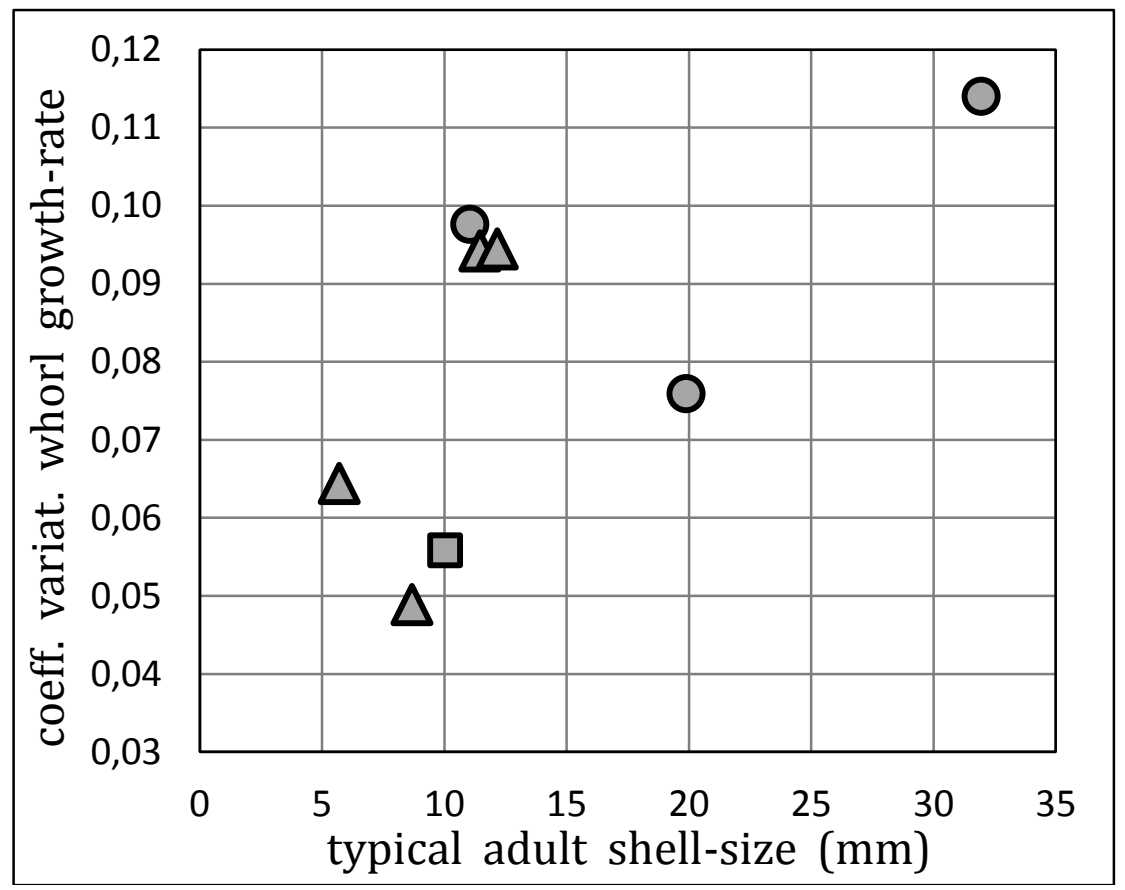

Fig. 3. The coefficients of variation of the whorl-growth parameter y plotted against a typical index of shell size $\left(\left[\mathrm{h} . \mathrm{d}^{2}\right]^{1 / 3}\right)$ for each eight studied land snail species. Shell-shape types: elongate shells: triangles, discoid shell: square, globular shells: discs 


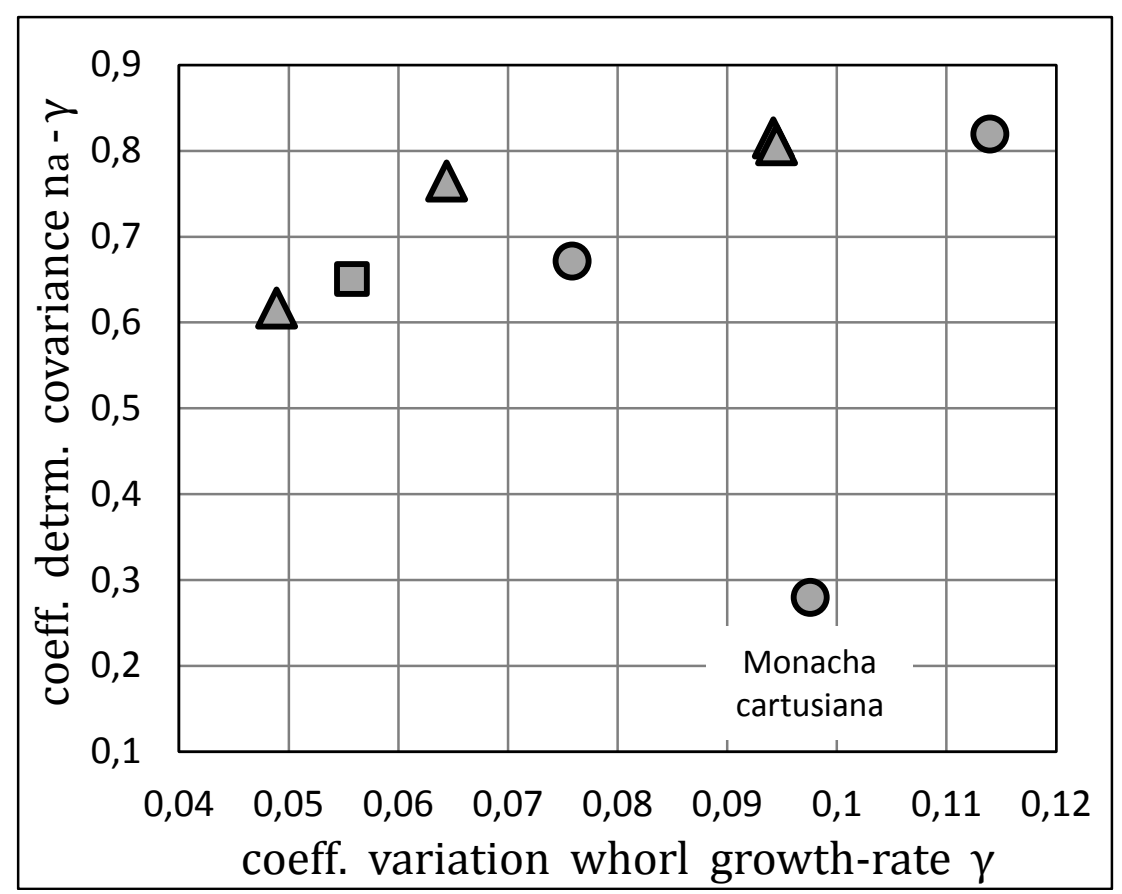

Fig. 4. The coefficient of determination $\left(r^{2}\right)$ of the negative covariance between $n_{a}$ and $y$, plotted against the coefficient of intra-specific variation of $y$, for each of the eight studied land snail species. No correlation is found $(r=0.10, n=8, p=0.81)$ when all eight species are considered. However, when Monacha cartusiana is excluded, a highly significant, positive correlation is found in agreement with expectation: $r=0.86, n=7, p=0.01$. Shell-shape types: elongate shells: triangles, discoid shell: square, globular shells: discs

The same being observed of course when the coefficient of correlation $r$ is considered, instead of $r^{2}$.

With, yet, the noticeable exception of one species, out of the eight studied: Monacha cartusiana. Now, the reason why this particular species singularizes apart from the seven other species, and stands out to such an extent, yet remains unknown.

\section{CONCLUSION}

Although the respective amplitudes of intraspecific variability of the whorl-growth parameter $\mathrm{Y}$, according to species, might seem rather "moderate" as a whole, they can, however, markedly differ from one another, depending on species identity. A species-specificity echoed by a similar pattern of species-specificity for the degree of negative covariance between the whorl-growth parameter $y$ and the number $n_{a}$ of whorls reached at adulthood. Such a similarity could be expected from the (usual) concordance between the degree of intra-specific variability of $Y$ and the strength of the compensatory, negative covariance between $n_{a}$ and $y$ (Fig. 4).

\section{ACKNOWLEDGEMENTS}

Author would like to thank two anonymous Reviewers for their useful suggestions contributing to improve the original version of the manuscript.

\section{COMPETING INTERESTS}

Author has declared that no competing interests exist.

\section{REFERENCES}

1. Goodfriend GA. Variation in land-snail shell form and size and its causes: a review. Systematic Zoology. 1986;35(2):204-223.

2. Béguinot J. Adult shell-size regulation in conispirally-coiled shells: Evidence for a widespread negative covariance between whorls growth-rate and the final number of whorls in land snails. Annual Research \& Review in Biology. 2021;36(10):95-106. DOI: 10.9734/ARRB/2021/v36i1030439

3. Gould SJ. A developmental constraint in Cerion, with comments on the definition 
and interpretation of constraint in evolution. Evolution. 1989;43(3):516-539.

4. Gould SJ, Paull C. Natural history of Cerion. VII. Geographic variation in Cerion (Mollusca: Pulmonata) from the eastern end of its range (Hispaniola to the Virgin Islands): Coherent patterns and taxonomic simplification. Breviora. 1977;445:1-24.

5. Kerney MP, Cameron RAD. Land Snails of Britain and North-West Europe. Collins \& Sons Publishers, London; 1979.

6. Raup DM. The geometry of coiling in gastropods. Proceedings of the National Academy of Science USA. 1961;47:602609.

7. Raup DM. Geometric analysis of shell coiling: general problems, Journal of Paleontology. 1966;40(5):1178-1190.
8. Acckerly SC. - Shell coiling in Gastropods: Analysis by stereographic projection. Palaios. 1989;4:374-378.

9. Hutchinson JMC. Control of gastropod shell shape; the role of the preceding whorl. Journal of theoretical Biology. 1989;140:431-444.

10. Hutchinson JMC. Control of gastropod shell form via apertural growth rate. Journal of Morphology. 1990;206:259-264.

11. Rice SH. The bio-geometry of mollusc shells. Paleobiology. 1998;24(1):133-149.

12. VAN Osselaer C, Grosjean P. Suture and location of the coiling axis in gastropod shells. Paleobiology. 2000;26(2):238-257.

13. Clements R, Liew TS, Vermeulen JJ, Schilthuizen M. Further twists in gastropod shell evolution. Biology Letters. 2008;4:179-182. 


\section{APPENDIX}

Disentangling and quantifying the respective contributions of growth parameters ' $n_{a}$ ' and ' $\gamma$ ' to the overall shell-size in conispirally-coiled shells

For those gastropod species with shell coiling geometry fairly approaching a conospiral profile and approximately answering the ideal exponential model (i.e. logarithmic spiral coiling), the contribution, $\delta_{i}$, of whorl number ' $i$ ' to the overall shell dimensions $\Delta$ (shell height or shell width) is, according to [613]:

$$
\Delta_{\mathrm{i}}=\delta_{1} \cdot \varepsilon^{(\mathrm{i}-1)}
$$

where:

- $\delta_{1}$ is the contribution of whorl number one ;

- $\varepsilon$ is the rate of whorl expansion (and, as well, the ratio between the contributions of two successive whorls: $\varepsilon=\delta_{i+1} / \delta_{\mathrm{i}}$ ).

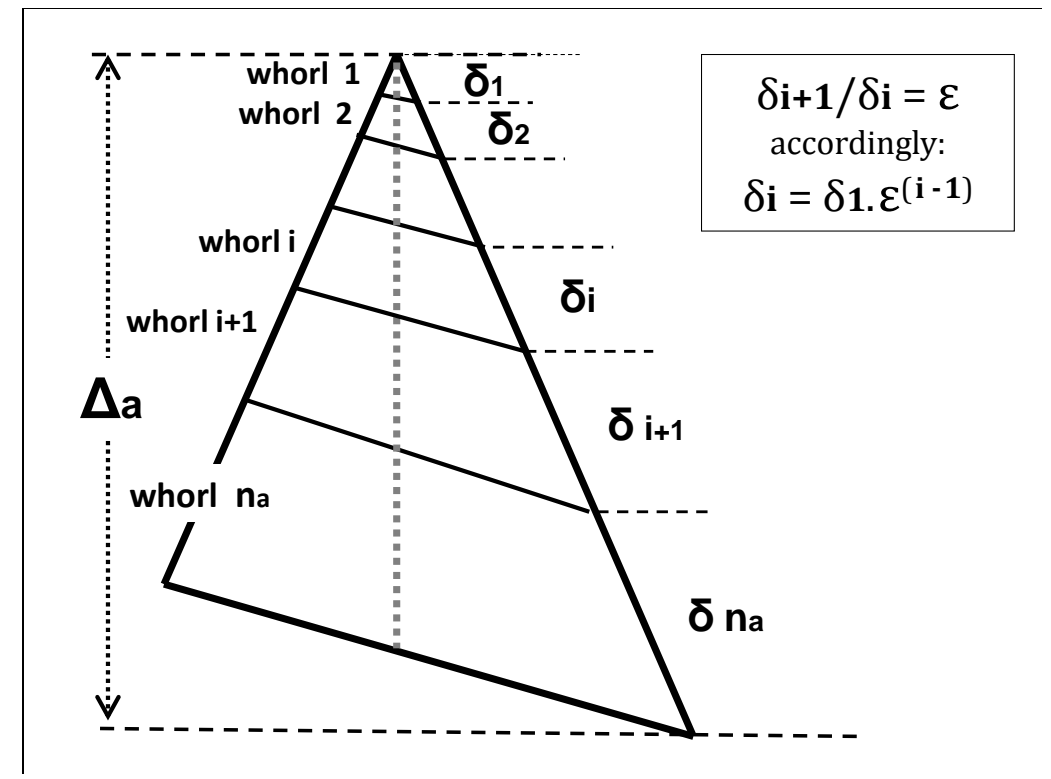

Fig. A1. Schematic sketch of the section of an ideally conispirally coiled shell, showing the morphometric parameters involved in this study: $n_{a}$ the number of whorls at adult stage; $\delta_{i}$ the contribution to shell-height of the $\mathrm{i}^{\text {th }}$ whorl $; \varepsilon$ the ratio of expansion of whorl section per revolution; $\Delta_{\mathrm{a}}$ the final, adult shell size. Here, for an elongated shell shape, the overall shell size is identified to shell height. But alternatively, a globular or discoidal shell shape would answer a similar schematic sketch with, accordingly, the overall shell size taken as the shell diameter (after reference [2])

Then, for a shell with $n$ whorls, the shell size is the sum of these $n$ successive contributions:

$$
\begin{aligned}
& \Delta(n)=\sum_{i=1 \text { to } n}\left(\delta_{i}\right)=\sum_{i=1 \text { to } n}\left(\delta_{1} \cdot \varepsilon^{(i-1)}\right)=\left[\delta_{1} /(\varepsilon-1)\right] \cdot\left(\varepsilon^{n}-1\right) \\
& \Delta(n)=c .\left(\varepsilon^{n}-1\right)
\end{aligned}
$$

with $\Sigma_{i=1}$ to $n$ designing the summation extended to the $n$ whorls of the shell and $c=\left[\delta_{1} /(\varepsilon-1)\right]$

The size of a shell reaching its adult stage, with a corresponding number $n_{a}$ of whorls, is thus $\Delta_{a}(=$ $\left.\Delta\left(\mathrm{n}_{\mathrm{a}}\right)\right)$ defined as follows: 


$$
\Delta_{\mathrm{a}}=\mathrm{c} \cdot\left(\varepsilon^{\mathrm{na}}-1\right)=\left[\delta_{1} /(\varepsilon-1)\right] \cdot\left(\varepsilon^{\mathrm{na}}-1\right)
$$

Some more or less limited discrepancies may exist, of course, between the specific reality and the idealised, classical coni-spiral model involving whorls contributions regularly increasing exponentially with the whorl numbering label. Yet, here, focus is placed on the inter-individual variability and we are dealing with variations of shell size, rather than with the estimates of size itself. As first order discrepancy regarding the absolute values taken by a parameter have only second-order influence upon the interindividual variations of this parameter, using the idealised classical model features appropriate to the subject under study.

\section{Defining a synthetic parameter ' $\gamma$ ' accounting for the combined contributions of growth parameters $\delta_{1}$ and $\varepsilon$}

The procedure, originally defined in [2], is summarized hereafter. The parameters $\delta_{1}$ and $\varepsilon$ govern together the geometry of progressive shell development (equation A2). Either or both parameters are subjected to intra-specific variability, inducing in turn, an inter-individual variability of the shell size reached at any given number of whorls. As for any other phenotypic character, the intra-specific variability of shell growth parameters may conveniently be considered by reference to a conventionally defined "type specimen" (characterised by the referential values $\delta_{1}{ }^{*}$ and $\varepsilon^{*}$ of parameters $\delta_{1}$ and $\varepsilon$ respectively).

The consequence on the adult-shell size of the intra-specific variability of growth parameters $\delta_{1}$ and/or $\varepsilon$ may then be quantified by the variations of the ratio:

$$
Y=\Delta_{\mathrm{a}} / \Delta_{\mathrm{a}}^{*}
$$

where:

$\Delta_{\mathrm{a}}$ is the adult size of the shell under consideration;

- $\quad \Delta_{\mathrm{a}}{ }^{*}$ is the size that the type specimen (or any specimen having the same parameters $\delta_{1}{ }^{*}$ and $\varepsilon^{*}$ ) would take for a number of whorls equal to the number of whorls $n_{a}$ of the adult-shell under consideration. The value of $\Delta_{\mathrm{a}}{ }^{*}$ is provided by equation (A2) with $\delta_{1}=\delta_{1}{ }^{*}$ and $\varepsilon=\varepsilon^{*}$ :

$$
\Delta_{\mathrm{a}}{ }^{*}=\mathrm{c}^{*} \cdot\left(\varepsilon^{* \text { na }}-1\right), \text { with } \mathrm{c}^{*}=\delta_{1}^{*} /\left(\varepsilon^{*}-1\right)
$$

Thus defined, the parameter $\mathrm{y}$ integrates the influence of $\delta_{1}$ and $\varepsilon$ on the geometrical development of the shell all along its ontogeny (via $\varepsilon$ ) and since its very beginning (via $\left.\delta_{1}\right)$. Although there is, of course, no possibility of disentangling the respective contributions to $Y$ of parameters $\delta_{1}$ and $\varepsilon$, it remains that $\mathrm{y}$ conveniently accounts for the combined contributions of $\delta_{1}$ and $\varepsilon$ to the overall shell size $\Delta$, at any given value of the number of whorls, by reference to a freely chosen type specimen of the corresponding species.

Parameter y may thus be aptly designed as a comprehensive "whorl-growth parameter". Moreover, from a practical point of view, this parameter $\mathrm{y}$ benefits by its particularly easy evaluation, only requiring the simple measurement of the adult-shell size $\Delta_{a}$, subsequently introduced in equation (A3), while the more delicate measurements of $\delta_{1}$ and of $\varepsilon$ pertaining to the type specimen had to be carried out only once and for all, and then introduced in equation (A4).

\section{A.3 - Practical procedure}

Consider a population of adult individuals (belonging to a same species having been previously typified with a referential "type specimen", in terms of the values of $\delta_{1}{ }^{*}$ and $\varepsilon^{*}$ ) submitted to a morphometric study. For each individual, both the number of whorls $n_{a}$ and the shell size $\Delta_{a}$ are measured, the later by using a numeric calliper and the former by careful examination from shell apex (according to procedure described in [5]) under stereo-microscope at moderate magnification, typically allowing a precision at a level of $1 / 10$ whorl revolution. Now, introducing the measured values $\delta_{1}{ }^{*}$ and $\varepsilon^{*}$ in equation (4) provides the value of $\Delta_{a}{ }^{*}$. Then, introducing the measured value of $\Delta_{\mathrm{a}}$ in 
equation (3) provides the values of the worl-growth parameter $y$ for each of the individual shells under study. Thus, the growth components $\mathrm{n}_{\mathrm{a}}$ and $\mathrm{y}$ (that have together determined the adult shell size $\Delta_{\mathrm{a}}$ ) are thus conveniently and easily made available for each member individual of the population under study.

(0) 2021 Béguinot; This is an Open Access article distributed under the terms of the Creative Commons Attribution License (http://creativecommons.org/licenses/by/4.0), which permits unrestricted use, distribution, and reproduction in any medium, provided the original work is properly cited.

Peer-review history:

The peer review history for this paper can be accessed here:

https://www.sdiarticle5.com/review-history/77388 